\section{Anesthetic Management in Birt-Hogg-Dubé Syndrome with Spontaneous and Recurrent Pneumothorax during Recovery after Laparoscopic-Assisted Partial Nephrectomy}

\section{Cheol Lee\#, Cheolhyeong Lee*, Hoyeon Jang and Juhwan Lee*}

Department of Anesthesiology and Pain Medicine, Wonkwang University School of Medicine, Iksan, South Korea

\#Equally contributed to this study

\begin{abstract}
Birt-Hogg-Dubé Syndrome (BHDS) is a hereditary condition associated with skin fibrofolliculomas, multiple lung cysts, and kidney tumors. We report a case of Birt-Hogg-Dubé Syndrome confirmed by folliculin (FLCN) genetic testing in a 45-year-old femalepatient with spontaneous and recurrent pneumothorax during recovery after laparoscopic-assisted partial nephrectomy.
\end{abstract}

Keywords: Birt-Hogg-Dubé Syndrome; Folliculin; Pneumothorax

\section{Introduction}

Birt-Hogg-Dubé Syndrome (BHDS) is an inherited autosomal dominant disorder associated with 3 clinical manifestations, including skin fibrofolliculomas, multiple lung cysts and kidney tumors. These symptoms generally do not appear till adult. BHDS can be suggested by clinical manifestations but is definitively confirmed by molecular genetic testing to detect mutations in the FLCN gene [1-4].

The pulmonary manifestations of BHDS are common findings and mainly related to multiple lung cysts and development of spontaneous pneumothorax. In the rate of occurrence of pneumothorax, patients

*Corresponding author: Juhwan Lee, Department of Anesthesiology and Pain Medicine, Wonkwang University School of Medicine, Iksan, South Korea, Tel: +82 638591561, E-mail: ironyii70@gmail.com

Citation: Lee C, Lee C, Jang H, Lee J (2019) Anesthetic Management in BirtHogg-Dubé Syndrome with Spontaneous and Recurrent Pneumothorax during Recovery after Laparoscopic-Assisted Partial Nephrectomy. J Anesth Clin Care 6: 35 .

Received: May 7, 2019; Accepted: May 13, 2019; Published: May 20, 2019

Copyright: ( 2019 Lee C, et al. This is an open-access article distributed under the terms of the Creative Commons Attribution License, which permits unrestricted use, distribution, and reproduction in any medium, provided the original author and source are credited. with BHDS have a 50-fold increase after adjusting for age. The management of pulmonary manifestations of BHDS largely focused on the approach to treatment of pneumothorax [1].

Postoperative respiratory complications have diverse etiologies and commonly occur in the Post-Anesthesia Care Unit (PACU) and hospital wards. Sometimes they are potentially life-threatening complications of anesthesia. Appropriate response to respiratory complications involves early intervention, development of a differential diagnosis, and an organized approach to respiratory support and patient disposition [2].

Therefore, we present a case of BHDS with spontaneous and recurrent pneumothorax during recovery after laparoscopic partial nephrectomy.

\section{Case Report}

One month prior to presentation, a 45-year-old woman had medical check-up in private clinic and was referred for evaluation and treatment of right renal mass. She was a non-smoker with no previous episodes of pneumothorax, and had been treated with $\mathrm{CO}_{2}$ laser and dermatologic ointment for multiple round shaped papules on face and neck but with little effect. She received Laparoscopically Assisted Vaginal Hysterectomy (LAVH) for uterine leiomyoma 3 years ago. Her family history was nonspecific and not notable.

A Chest X-ray (CXR) was nonspecific (Figure 1A) and abdominopelvic Computed Tomography (CT) showed multiple hepatic hemangioma and about $1 \mathrm{~cm}$ sized solid mass on Rt. lower pole at right kidney. She underwent laparoscopic partial nephrectomy for the solid mass. Carbon dioxide is insufflated into the peritoneal cavity at a rate of 4-6 liter/min to a pressure of $12-16 \mathrm{~mm} \mathrm{Hg}$. Anesthetic managements were applied to the patient; Tidal volume $12-15 \mathrm{ml} /$ $\mathrm{kg}$, respiratory rate $10-12$ breaths/min to maintain end tidal $\mathrm{CO}_{2} 35$ $40 \mathrm{mmHg}$ and PEEP $5 \mathrm{~cm} \mathrm{H}_{2} \mathrm{O}$. The patient's vital signs were not eventful during surgery. The patient was given intravenous analgesics using a PCA pump containing morphine $(60 \mathrm{mg})$, ketorolac $(150 \mathrm{mg})$, and ramosetron $(0.6 \mathrm{mg})$ in a total volume of $100 \mathrm{ml}$ of saline.

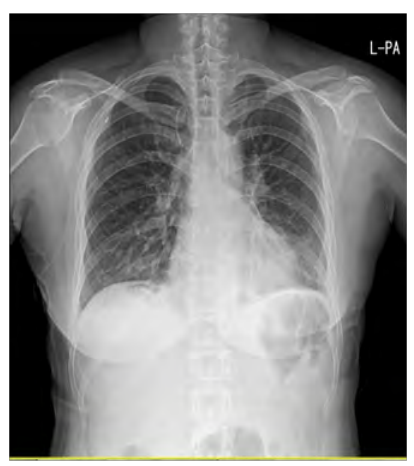

Figure 1A: Chest $\mathrm{x}$-ray on admission show normal 
Citation: Lee C, Lee C, Jang H, Lee J (2019) Anesthetic Management in Birt-Hogg-Dubé Syndrome with Spontaneous and Recurrent Pneumothorax during Recovery after Laparoscopic-Assisted Partial Nephrectomy. J Anesth Clin Care 6: 35.

She complained chest pain and short of breath after moving to PACU. The patient had normal vital signs and diminished breathing sound of both lungs on auscultation. CXR and Electrocardiography (EKG) were taken and Arterial Blood Gas Analysis (ABGA) was examined. EKG was normal and CXR showed both pneumothoraxes (Figure 1B). ABGA revealed pH 7.41, $\mathrm{PCO}_{2} 36.1, \mathrm{PO}_{2} 90.6$, and $\mathrm{HCO}_{3}$ 22.5. The patient was consulted to cardiothoracic surgeon regarding the pneumothorax.

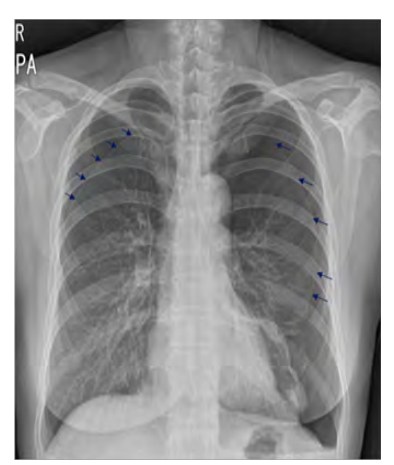

Figure 1B: Chest $x$-ray in PACU after laparoscopic partial nephrectomy shows both pneumothorax (small arrows).

After bilateral tube thoracostomy, chest CT (Figure 2A) was taken and showed multiple, variable shaped cystic lesions with random distribution, and moderate to large amount of pneumothorax on both lung and sub segmental atelectasis on right lung. Pulmonary function test (\% predicted) revealed FVC 72, FEV1 77, FEV1/FVC 78 and DLCO 68, which were restrictive pattern in this patient.

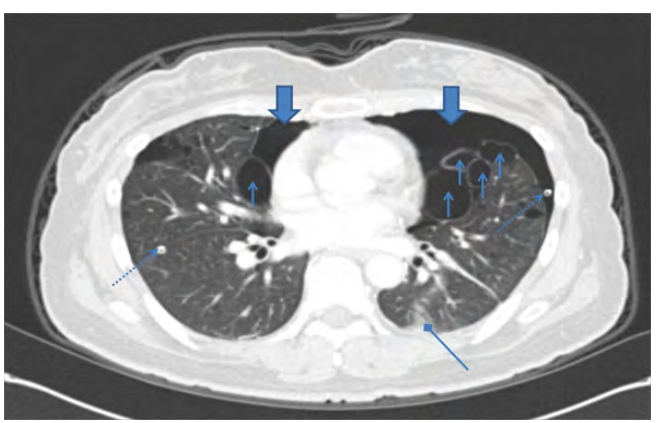

Figure 2A: Chest CT after thoracotomy shows improving state of pneumothorax in both hemithorax (big arrow), multiple variable sized cystic lesion with random distribution in lung field (small arrow), malposition of Rt. chest tube with tip in the lung parenchyme and Lt. chest tube (dotted line arrow) and sub segmental atelectasis (diamond arrow).

One week later, she underwent Video-Assisted Thoracoscopic Surgery (VATS). Lymphangioleiomyomatosis (LAM) affects predominantly women with reproductive age and is characterized by multiple cysts scattered throughout both lung fields. Given medical history with leiomyoma, multiple lung cysts and pneumothorax, at first, LAM was suspected. However, skin lesions including several flesh-colored, dome-shaped papules on physical examination, fibrofolliculomas on skin biopsy and oncocytoma finding on permanent section of right partial nephrectomy strongly suggested BHDS. It was diagnosed and confirmed by FLCN gene mutation on genetic examination. She discharged home after recovering from laparoscopic partial nephrectomy and VATS. One week later, she admitted to hospital again owing to dyspnea and chest pain. ABGA showed $\mathrm{pH}$ 7.44, $\mathrm{PCO}_{2} 34, \mathrm{PO}_{2} 135, \mathrm{HCO}_{3}$ 23.1. CXR revealed the right pneumothorax (Figure 1C). Anesthetic managements including no PEEP, tidal volume $3-4 \mathrm{ml} / \mathrm{kg}$, respirate rate $15-18$ breaths $/ \mathrm{min}$ to maintain end-tidal $\mathrm{CO}_{2} 35-40 \mathrm{mmHg}$, and peak airway pressure $35-40 \mathrm{mmHg}$ or manual ventilation to prevent over-expand bullae were applied to the patient during VATS. Following appropriate catheter insertion, an initial bolus dose with local anesthetics was given and a continuous epidural infusion was started with a mixture of bupivacaine $2.5 \mathrm{mg}$ / $\mathrm{ml}$ and morphine $0.04 \mathrm{mg} / \mathrm{ml}$. An i.v. dose of ketorolac $30 \mathrm{mg}$ was administered if patients reported a VAS score $\geq 40$, and $15 \mathrm{mg}$ ketorolac was added as needed during PACU stay.

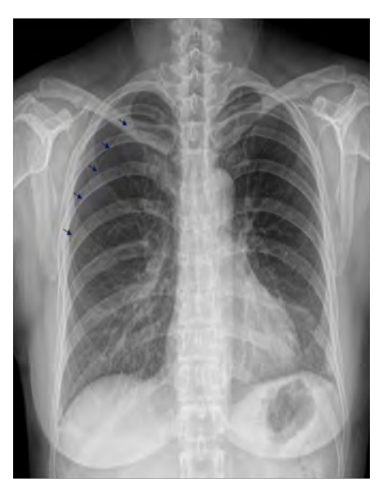

Figure 1C: Chest $\mathrm{x}$-ray 1 week later shows right pneumothorax (small arrow).

Cyst rupture during induction and subsequent release of contents into a tracheobronchial tree were not shown. Six months later, her chest CT (Figure 2B) showed resolved pneumothorax, and no significant interval change of multiple variable sized cystic lesions with random distribution in both lungs.

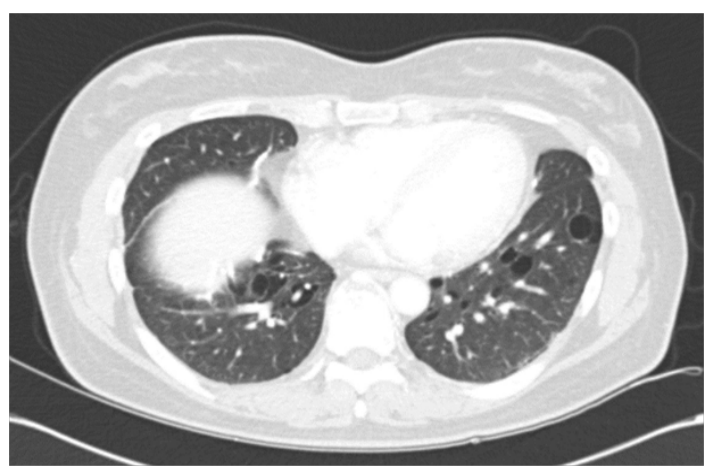

Figure 2B: Chest CT after 6 month's shows resolved pneumothorax.

\section{Discussion}

In present case, the patient had no symptoms and signs of BHDS except skin lesions. The patient knew renal mass incidentally on medical checkup performed in private clinic. Chest CT for recurrent pneumothorax after surgery, permanent section finding of partial nephrectomy, skin biopsy and genetic study confirmed BHDS in this patient. Although BHDS is an inherited autosomal dominant disorder, her family history was nonspecific. Like this case, the pattern of mutations and spectrum of symptoms are heterogeneous between 
ividuals. Therefore the diagnosis is sometimes delayed because of variability in its expression and unfamiliarity to many physicians.

The multiple lung cysts in BHDS do not cause problems with breathing and but increase risk of spontaneous pneumothorax, which may result in a collapsed lung. A Korean study with BHDS reported that most of the patients had $91.7-100 \%$ lung cysts. Pneumothorax developed in $66.7 \%$ and $75 \%$ was recurrent. However, LAM, pulmonary Langerhans cell histiocytosis, lymphocytic interstitial pneumonia/follicular bronchiolitis, and amyloidosis should be considered in patients with multiple lung cysts [5].

In present case, chest $\mathrm{CT}$ showed that multiple lung cysts, pneumothorax, and atelectasis, after spontaneous pneumothorax during recovery after surgery. Multiple lung cysts and uterine leiomyoma strongly suspected LAM among cystic lung diseases, before skin biopsy and gene study were performed. PFT in most of the patients with BHDS show percentages of normal predicted values, although mild restrictive pattern in some patients is detected $[3,6,7]$. Our patient had restrictive pattern in PFT with dyspnea after first pneumothorax occurred.

The first spontaneous pneumothorax on both lungs in this patient might be triggered from laparoscopic partial nephrectomy and conventional anesthetic management. Laparoscopy induced pneumoperitoneum, long duration of surgery and Positive End-Expiratory Pressure (PEEP) applied during surgery might cause rupture of multiple large bullae on both lungs. However, based on uneventful vital signs and airway pressure during surgery, postoperative rupture of the cysts was suspected. Our authors should have paid scrupulous attention to anesthetic management for the patient during the surgery, if we'd known the patient was BHDS.

When the second pneumothorax on right lung in the patients occurred, BHDS was diagnosed earlier. Although treatment in a patient who have pneumothorax with BHDS is similar for sporadic primary pneumothorax $[2,6]$, the careful anesthetic managements including small tidal volume, no PEEP, lower peak airway pressure (20-25 $\mathrm{mmHg}$ ), or manual ventilation to avoid application of excessive pressure at any point during a respiratory cycle and active pain management with epidural analgesia were applied to our patient.
In conclusion, BHDS with multiple intrathoracic cysts carry the risk of rupture peri-anesthetic period. When a patient with BHDS complains chest pain or dyspnea in perioperative period, pneumothorax may be first thing anesthesiologists should consider. The scrupulous anesthetic management and active pain management in patients with BHDS should be required to prevent postoperative pneumothorax.

\section{Conflict of Interest}

No potential conflict of interest relevant to this article was reported.

\section{References}

1. Gupta N, Seyama K, McCormack FX (2013) Pulmonary manifestations of Birt-Hogg-Dubé Syndrome. Fam Cancer 12: 387-396.

2. Özer E, Pampal HK, Dakak M (2012) Multiple lung cysts and Birt-HoggDubé Syndrome: management of anaesthesia and Surgery. Gulhane Med J 54: 302-305

3. Lee JH, Jeon MJ, Song JS, Chae EJ, Choi JH, et al. (2018) Birt-HoggDubé Syndrome in Korean: clinicoradiologic features and long term follow-up. Korean J Intern Med.

4. Aivaz O, Berkman S, Middelton L, Linehan WM, DiGiovanna JJ, et al. (2015) Comedonal and Cystic Fibrofolliculomas in Birt-Hogg-Dube Syndrome. JAMA Dermatol 151: 770-774.

5. Park S, Lee EJ (2017) Diagnosis and treatment of cystic lung disease. Korean J Intern Med 32: 229-238.

6. Menko FH, van Steensel MA, Giraud S, Friis-Hansen L, Richard S, et al. (2009) Birt-Hogg-Dubé syndrome: diagnosis and management. Lancet Oncol 10: 1199-206.

7. Predina JD, Kotloff RM, Miller WT, Singhal S (2011) Recurrent spontaneous pneumothorax in a patient with Birt-Hogg-Dubé syndrome. Eur J Cardiothorac Surg 39: 404-406. 


\section{Hit}

Journal of Anesthesia \& Clinical Care

Journal of Addiction \& Addictive Disorders

Advances in Microbiology Research

Advances in Industrial Biotechnology

Journal of Agronomy \& Agricultural Science

Journal of AIDS Clinical Research \& STDs

Journal of Alcoholism, Drug Abuse \& Substance Dependence

Journal of Allergy Disorders \& Therapy

Journal of Alternative, Complementary \& Integrative Medicine

Journal of Alzheimer's \& Neurodegenerative Diseases

Journal of Angiology \& Vascular Surgery

Journal of Animal Research \& Veterinary Science

Archives of Zoological Studies

Archives of Urology

Journal of Atmospheric \& Earth-Sciences

Journal of Aquaculture \& Fisheries

Journal of Biotech Research \& Biochemistry

Journal of Brain \& Neuroscience Research

Journal of Cancer Biology \& Treatment

Journal of Cardiology: Study \& Research

Journal of Cell Biology \& Cell Metabolism

Journal of Clinical Dermatology \& Therapy

Journal of Clinical Immunology \& Immunotherapy

Journal of Clinical Studies \& Medical Case Reports

Journal of Community Medicine \& Public Health Care

Current Trends: Medical \& Biological Engineering

Journal of Cytology \& Tissue Biology

Journal of Dentistry: Oral Health \& Cosmesis

Journal of Diabetes \& Metabolic Disorders

Journal of Dairy Research \& Technology

Journal of Emergency Medicine Trauma \& Surgical Care

Journal of Environmental Science: Current Research

Journal of Food Science \& Nutrition

Journal of Forensic, Legal \& Investigative Sciences

Journal of Gastroenterology \& Hepatology Research

Journal of Gerontology \& Geriatric Medicine
Journal of Genetics \& Genomic Sciences

Journal of Hematology, Blood Transfusion \& Disorders

Journal of Human Endocrinology

Journal of Hospice \& Palliative Medical Care

Journal of Internal Medicine \& Primary Healthcare

Journal of Infectious \& Non Infectious Diseases

Journal of Light \& Laser: Current Trends

Journal of Modern Chemical Sciences

Journal of Medicine: Study \& Research

Journal of Nanotechnology: Nanomedicine \& Nanobiotechnology

Journal of Neonatology \& Clinical Pediatrics

Journal of Nephrology \& Renal Therapy

Journal of Non Invasive Vascular Investigation

Journal of Nuclear Medicine, Radiology \& Radiation Therapy

Journal of Obesity \& Weight Loss

Journal of Orthopedic Research \& Physiotherapy

Journal of Otolaryngology, Head \& Neck Surgery

Journal of Protein Research \& Bioinformatics

Journal of Pathology Clinical \& Medical Research

Journal of Pharmacology, Pharmaceutics \& Pharmacovigilance

Journal of Physical Medicine, Rehabilitation \& Disabilities

Journal of Plant Science: Current Research

Journal of Psychiatry, Depression \& Anxiety

Journal of Pulmonary Medicine \& Respiratory Research

Journal of Practical \& Professional Nursing

Journal of Reproductive Medicine, Gynaecology \& Obstetrics

Journal of Stem Cells Research, Development \& Therapy

Journal of Surgery: Current Trends \& Innovations

Journal of Toxicology: Current Research

Journal of Translational Science and Research

Trends in Anatomy \& Physiology

Journal of Vaccines Research \& Vaccination

Journal of Virology \& Antivirals

Archives of Surgery and Surgical Education

Sports Medicine and Injury Care Journal

International Journal of Case Reports and Therapeutic Studies

Submit Your Manuscript: http://www.heraldopenaccess.us/Online-Submission.php 